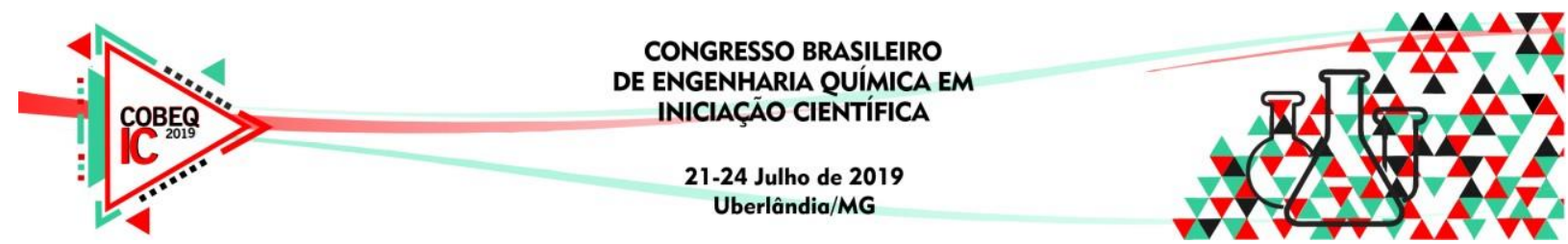

\title{
REAPROVEITAMENTO DO ÓLEO RESIDUAL DE FRITURA PARA A PRODUÇÃO DE BIODIESEL VIA CATÁLISE ÁCIDA E BÁSICA
}

\author{
L.P. LADEIRA ${ }^{1}$, C.S.S. PEREIRA ${ }^{1}$, S.P. RIBEIRO ${ }^{1}$, \\ F.F.N.PETRAGLIA ${ }^{1}$, E.F.GUIMARÃES ${ }^{1}$ \\ ${ }^{1}$ Universidade de Vassouras, Curso de Engenharia Química \\ E-mail para contato: lpladeira1998@gmail.com
}

\begin{abstract}
RESUMO - O biodiesel é um combustível biodegradável que pode ser produzido a partir de gorduras animais ou de óleos vegetais, sendo estes os mais utilizados. Neste trabalho, realizou-se a produção do biodiesel através da transesterificação via catálise básica e por via ácida utilizando óleo de fritura como matéria prima. O óleo foi purificado através do processo de filtração em camadas. Para a catálise básica utilizou-se metanol e hidróxido de potássio e para a catalise ácida utilizouse metanol e ácido sulfúrico. As amostras de biodiesel foram caracterizadas por espectroscopia na região do infravermelho médio (FTIR). Avaliou-se a viscosidade do biodiesel utilizando um viscosímetro de Brookfield. Diante dos resultados obtidos observou-se que a catálise básica apresentou maior rendimento $(86 \%)$ em comparação à catálise ácida $(75 \%)$. Além da motivação ao reuso do óleo residual de fritura como uma alternativa sustentável para a produção de biocombustíveis renováveis, o trabalho contribui também para a conscientização da população de Vassouras/RJ quanto a destinação sustentável do mesmo.
\end{abstract}

\section{INTRODUÇÃO}

$\mathrm{O}$ aumento da população associado ao aumento da energia consumida e à natureza finita de recursos fósseis conduziu à necessidade de se investigar alternativas energéticas sustentáveis. O biodiesel (um substituto menos poluente para o diesel) é um combustível biodegradável que pode ser produzido a partir de gorduras animais ou de óleos vegetais, sendo estes os mais utilizados. Fatores como geografia, clima e economia determinam os óleos vegetais mais interessantes para a produção de biodiesel. Esse é uma mistura de ésteres formados pela transesterificação de triacilglicerídeos, presentes em óleos e gorduras, com álcool de cadeia curta (geralmente metanol), na presença de uma base alcalina (bases fortes), ácido (ácidos fortes) ou catalisador enzimático.

O biodiesel tem propriedades lubrificantes melhores que o atual combustivel diesel, e menor teor de enxofre. Além de reduzir o desgaste do sistema de combustivel e aumentar a vida útil do equipamento de injeção que depende dele para a sua lubrificação. De acordo com a Agência Nacional do Petroleo, Gás Natural e Biocombustiveis (ANP) o biodiesel permite melhor lubrificação e uma combustão mais completa, aumentando assim a produção de energia do motor e compensando a maior densidade de energia do diesel. Estes podem ser produzidos a partir de óleos de cozinha, que às vezes são descartados de maneira inadequada. 


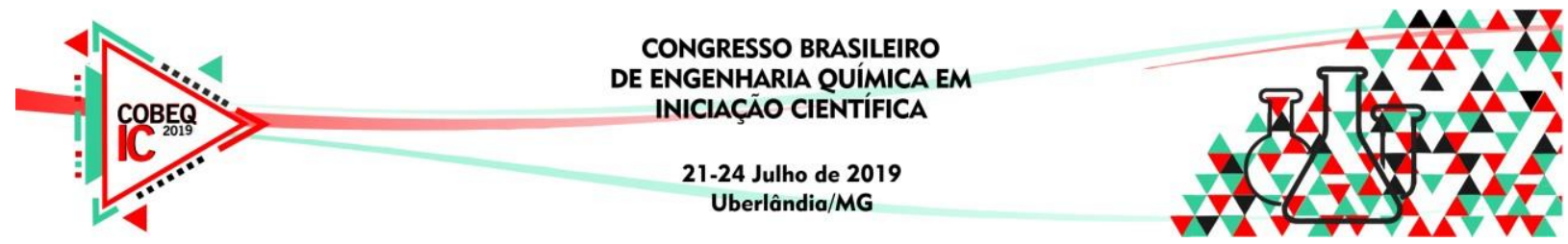

O biodisel pode ser usado puro ou em misturas com diesel. A nomenclatura para identificação destas misturas é definida como $\mathrm{BX}$, onde $\mathrm{X}$ corresponde à porcentagem de biodiesel na amostra, por exemplo, B10 corresponde a $10 \%$ de biodiesel e $90 \%$ de combustível fóssil. No Brasil, é obrigatório conter pelo menos $10 \%$ de biodiesel, desde março de 2018 .

A matéria prima utilizada para a produção do biodiesel é responsável por cerca de 60 a $80 \%$ do custo total de produção. Os catalisadores de altos rendimentos, como por exemplo, carbeto de silício $(\mathrm{SiC})$, carbeto de silício $(\mathrm{SiC})$ dopado com cobalto $(\mathrm{Co})$ e potássio $(\mathrm{K})$, zeólita ( $\mathrm{NaY}$ ) e alumina (Al2O3), são extremamente caros. Os catalisadores que serão utilizados na produção vão ser o ácido sulfúrico $\left(\mathrm{H}_{2} \mathrm{SO}_{4}\right)$ para a catálise ácida e o hidróxido de potássio $(\mathrm{KOH})$ para a catálise básica. E com isso minimizar os custos da produção.

\section{MATERIAIS E MÉTODOS}

\subsection{Matéria prima}

Para a reação de produção do biodiesel foram utilizadas amostras de óleos residuais de fritura recolhidos na cidade de Vassouras/RJ. Para a purificação do óleo realizou-se um processo de filtração utilizando como meio filtrante bagaço de cana, algas e resíduo oriundo do processo de cerveja.

\subsection{Reação de Transesterificação Via Catálise Básica}

Procedeu-se o preparo de uma solução de metóxido de potássio, dissolvendo-se $2 \mathrm{~g}$ de hidróxido de potássio $(\mathrm{KOH})$ em $45 \mathrm{~mL}$ de álcool metílico (metanol) com um auxílio de um agitador magnético e com controle de temperatura $\left(45^{\circ} \mathrm{C}\right)$ até completa diluição do hidróxido de potássio $(\mathrm{KOH})$. Em um balão de fundo chato $(500 \mathrm{~mL})$, adicionou-se $100 \mathrm{~mL}$ do óleo de fritura purificado e aqueceu-se em banha-maria, sob agitação, até atingir a temperatura de $45^{\circ} \mathrm{C}$. Em seguida, adicionou-se a solução de metóxido de potássio e a reação procedeu-se por 20 minutos à $45^{\circ} \mathrm{C}$ e agitação. Após este processo, transferiu-se a amostra para um funil de decantação para separação das fases, conforme apresentado na Figura 1.

Figura 1- Separação das fases do biodiesel. Superior (biodiesel) e inferior (glicerina).

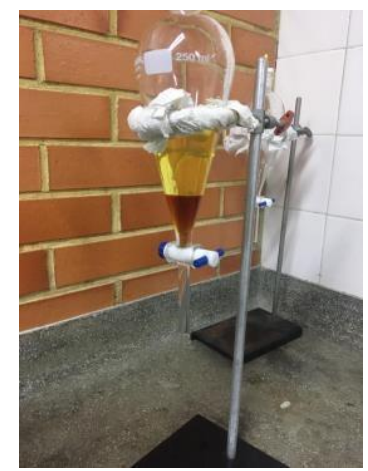

Para o procedimento de lavagem, adicionou-se uma solução de ácido clorídrico $1 \%$ (v/v). Após 10 minutos, realizou-se o processo de lavagem com $50 \mathrm{~mL}$ de solução saturada de 


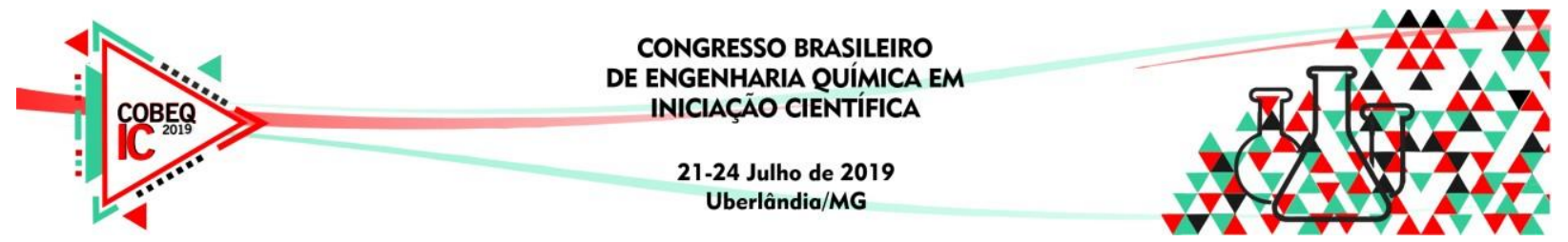

$\mathrm{NaCl}$ e e em seguida $50 \mathrm{~mL}$ de água destilada. O processo de lavagem ocorreu até a obtenção de um pH neutro. Para a remoção dos traços de umidade o biodiesel foi filtrado utilizando-se sulfato de sódio anidrido, como indicado no fluxograma da Figura 2.

\subsection{Preparação Do Biodiesel Via Catálise Ácida}

$\mathrm{Na}$ transesterificação via catálise ácida, Figura 2 (B) utilizou-se $100 \mathrm{~mL}$ de óleo a $65^{\circ} \mathrm{C}$. Adicionou-se ao mesmo uma mistura de $0,12 \mathrm{~mL}$ de ácido sulfúrico concentração $95 \%$ $\left(\mathrm{H}_{2} \mathrm{SO}_{4}\right)$ e $46 \mathrm{~mL}$ de metanol $(99,9 \%)$, mantendo-se sob agitação e aquecimento durante 6 horas. A reação foi seguida por uma mudança de cor, que passou de um amarelo opaco para um amarelo translúcido escuro e por uma decantação de 8 horas. Para a separação e lavagem do produto utilizou-se água destilada. Para a remoção de traços de umidade no produto realizou-se um processo de filtração utilizando-se sulfato de sódio anidro.

Figura 2- Preparação do biodiesel. (A) catálise básica e (B) catálise ácida

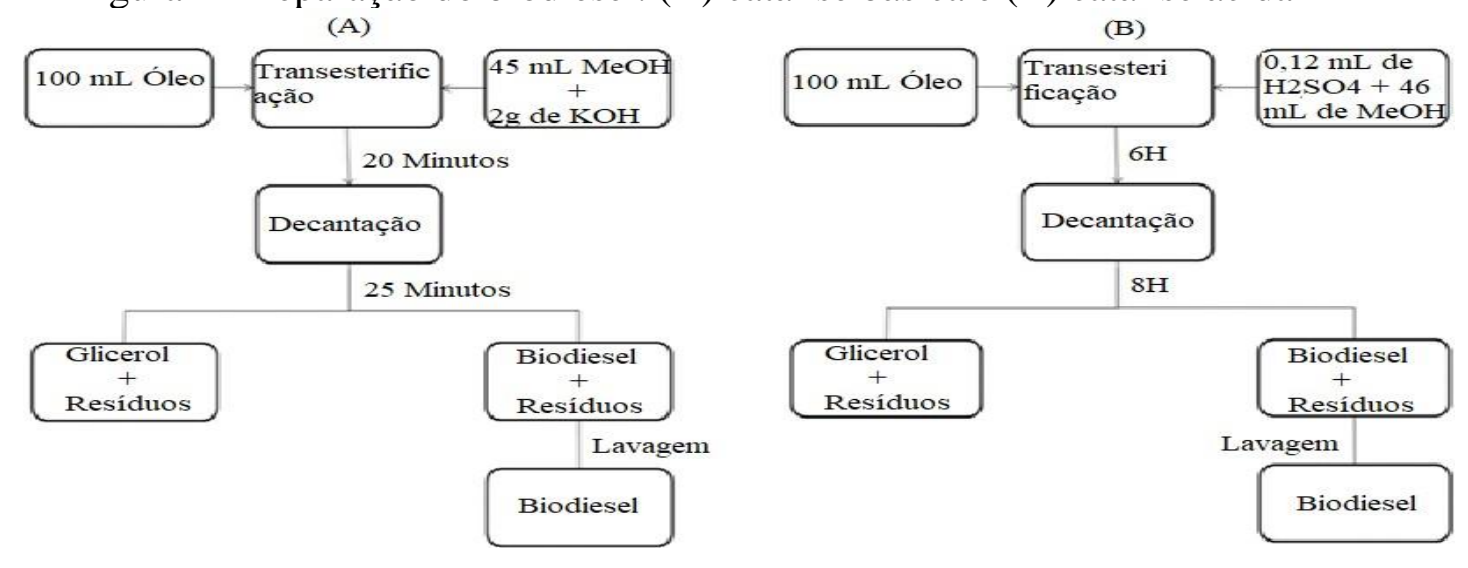

Os rendimentos da reação foram calculados a partir do volume inicial da matéria-prima com o volume de biodiesel produzido.

O biodiesel foi avaliado quanto à viscosidade em um viscosímetro de Brookfield e analisado por espectroscopia na região do infravermelho (FTIR). Os ensaios foram realizados utilizando pastilha de $\mathrm{KBr}$ com espaçador de $0,025 \mathrm{~mm}$. Realizou-se também um teste de queima do biodiesel.

\section{RESULTADOS E DISUSSÕES}

\subsection{Rendimento Do Biodiesel}

Os resultados do percentual obtidos da reação de transesterificação do óleo de fritura, utilizando-se os catalisadores $\mathrm{KOH}$ e $\mathrm{H}_{2} \mathrm{SO}_{4}$ foram de $86 \%$ para a básica e de $75 \%$ para a ácida. 


\subsection{Caracterização do Biodiesel}

Figura 3 - Espectroscopia na Região do Infravermelho médio (FTIR) da catálise básica.

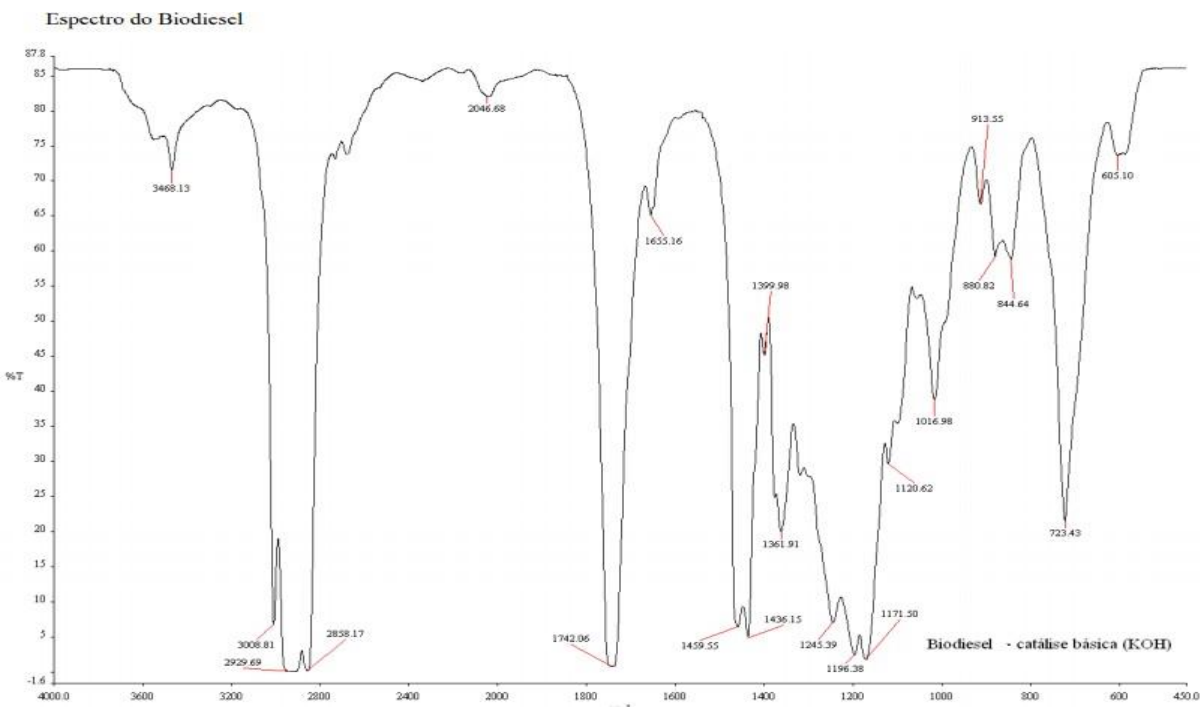

Figura 4 - Espectroscopia na Região do Infravermelho médio (FTIR) de uma catalise ácida.

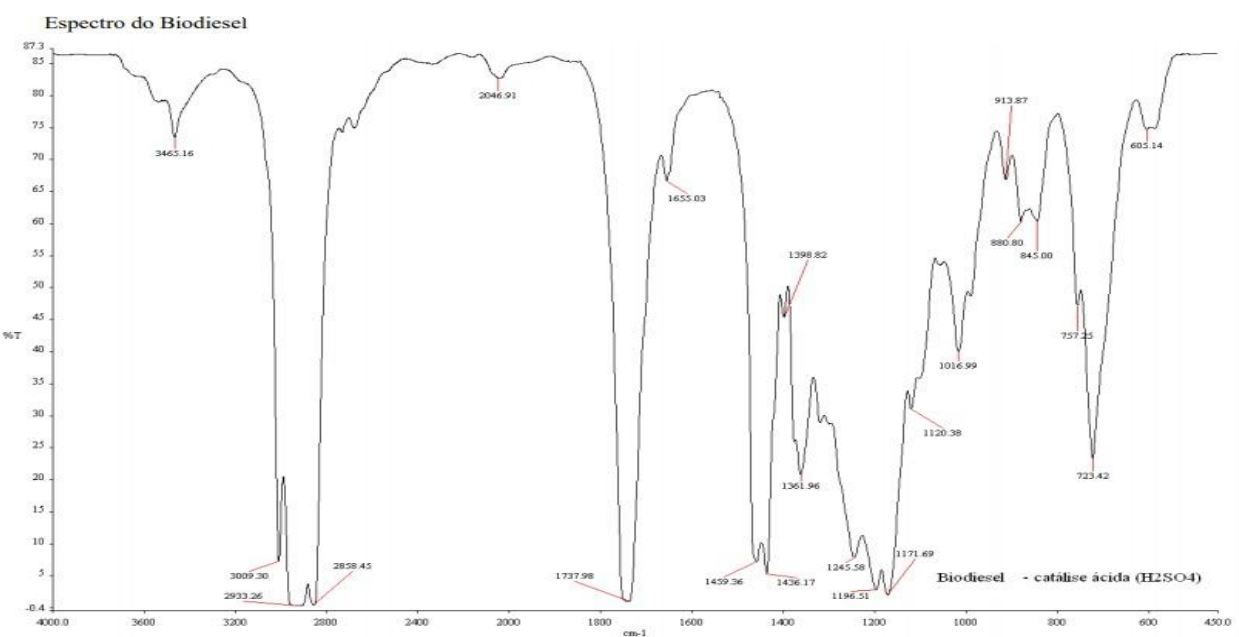

Os espectros das amostras de biodiesel apresentam bandas de absorção na região de $3000-2850 \mathrm{~cm}^{-1}$ características das vibrações de deformação axial das ligações C-H dos grupos metila $\left(\mathrm{CH}_{3}\right)$ e metileno $\left(\mathrm{CH}_{2}\right)$. As bandas que aparecem na região de 1300 a $1500 \mathrm{~cm}^{-}$ ${ }^{1}$ são provenientes das vibrações de deformação angular das ligações $\mathrm{C}-\mathrm{H}$ dos grupamentos metila e metileno e a banda que aparece na região de $725-720 \mathrm{~cm}^{-1}$ de cada espectro corresponde à deformação angular assimétrica do grupo $\mathrm{CH}_{2}$ (essas bandas são evidentes em compostos de cadeia longa e correspondem a vibração do fragmento $\left[\mathrm{CH}_{2}\right] \mathrm{n}$, onde $\mathrm{n} \geq 4$ ). A 


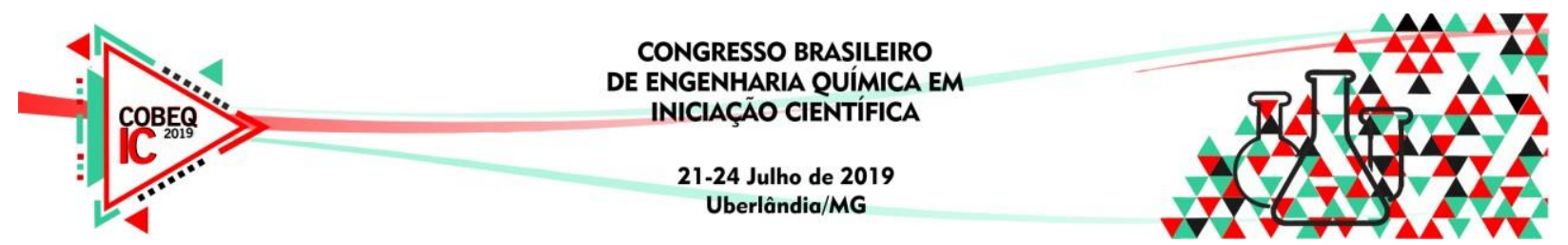

banda em cerca de $3010 \mathrm{~cm}^{-1}$ observada em cada espectro, corresponde às vibrações de deformação axial da ligação $\mathrm{C}-\mathrm{H}$ de ligação dupla e a banda em torno de $1655 \mathrm{~cm}^{-1}$ pode ser atribuída às vibrações de deformação axial da ligação $\mathrm{C}=\mathrm{C}$.

A banda de absorção presente em aproximadamente $3430-3475 \mathrm{~cm}^{-1}$ corresponde às vibrações de deformação axial do grupo hidroxila $(\mathrm{O}-\mathrm{H})$. Já a banda intensa na região de $1735-1750 \mathrm{~cm}^{-1}$ é própria de ésteres e se deve às vibrações de deformação axial do grupo carbonila $(\mathrm{C}=\mathrm{O})$ e as bandas fortes na região de 1000-1300 cm-1 são atribuídas às vibrações de deformação axial da ligação C-O.

\subsection{Viscosidade e Queima}

Após ensaios de viscosidade obteve-se um resultado de $0,850 \mathrm{~g} \mathrm{~cm}^{-3}$. Já o poder de queima ficou um pouco abaixo do normal, que foi 32,81 MJ/L. O poder calorífico do biodiesel segundo a Associação dos Produtores de Biodiesel do Brasil (APROBIO) é de 37,27 MJ/L, ele é 9\% inferior ao óleo diesel derivado de petróleo (APROBIO, 2017).

Figura 5- Teste de queima do biodiesel.

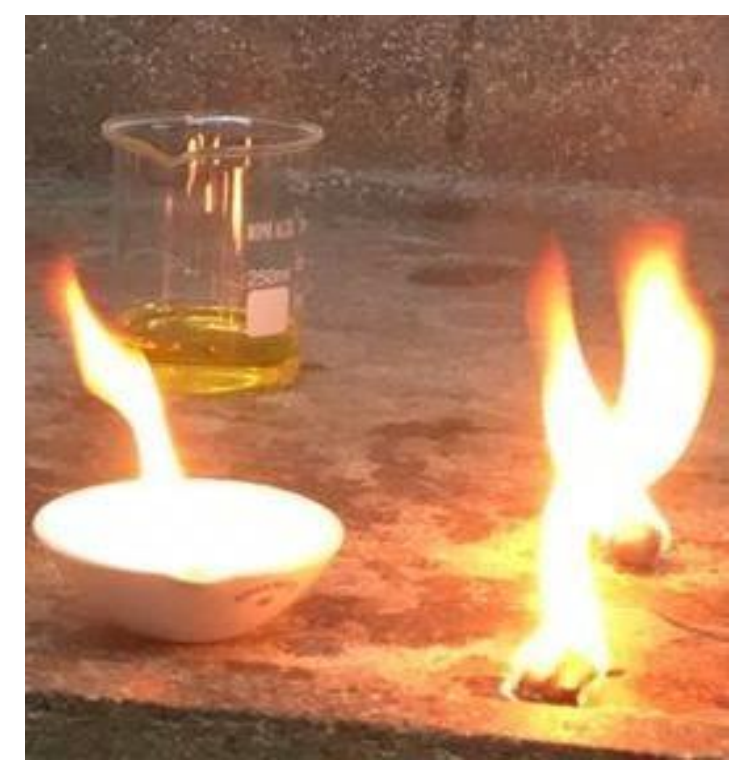

\section{CONCLUSÃO}

Conclui-se após resultados que a catálise básica apresenta maior rendimento (86\%) em comparação a catálise ácida (75\%). O estudo contribui como uma alternativa sustentável de reutilização do óleo de fritura e, também, com a conscientização da população e da comunidade acadêmica da Universidade de Vassouras/RJ. 


\section{REFERÊNCIAS}

BUESO, F., MORENO, L. CEDEÑO, M., MANZANAREZ, K. Lipase-catalyzed biodiesel production and quality with Jatropha curcas oil: exploring its potential for Central America. Journal of Biological Engineering, v.9:12, 2015

GERIS, R., Santos, N.A.C., Amaral, B.A., Maia, I.S., Castro, V.D., Carvalho, J.R.M., Biodiesel de Soja - Reação de transesterificação para aulas práticas de química orgânica. Quim. Nova, Vol. 30, No. 5, 1369-1373, 2007.

SILVERSTEIN, Robert M.; WEBSTER, Francis X. (Autor). Identificação espectrométrica de compostos orgânicos. 7. ed. Rio de Janeiro, RJ: LTC, 2007.

SHREVE, R.N.; BRINK Jr, J.A. Indústrias de Processos Químicos. Rio de Janeiro: Ed. Guanabara Koogan S.A., 1997. 